\title{
Disseminated Intravascular Coagulation Complicating Allogeneic Hematopoietic Stem Cell Transplantation
}

\author{
Shosaku Nomura \\ First Department of Internal Medicine, Kansai Medical University, Osaka, Japan
}

Disseminated intravascular coagulation (DIC) frequently complicates hematologic malignancies and infections [1]. Coagulation abnormalities and thrombocytopenia are common in DIC, and the extent of hemostatic disorders appears to correlate with disease severity. Allogeneic hematopoietic stem cell transplantation (aHSCT) incurs specific, serious, transplant-related complications, including DIC [2], and recovery from these complications is vital for achieving a successful aHSCT outcome. Therefore, taking steps to mitigate coagulation-related complications following aHSCT is very important. Several interactions between coagulation-related blood components and the fibrinolytic systems are involved in the progression of vascular angiopathy.

Recombinanthuman soluble thrombomodulin(rhTM) is composed of the active extracellular domain of thrombomodulin. Like membrane-bound thrombomodulin, rhTM binds to thrombin to inactivate coagulation. The resulting thrombin-rhTM complex acts to produce activated protein $\mathrm{C}$ which inactivates factors VIIIa and $\mathrm{Va}$ in the presence of protein $S$, thereby inhibiting further thrombin formation [3]. Based on the results of a Japanese clinical trial [3], medical insurance cover for rhTM in Japan was extended to DIC. In addition, there are some reports on the efficacy of rhTM therapies for veno-occlusive disease or thrombotic microangiopathy $[4,5]$. However, the effects of rhTM against DIC following aHSCT are poorly understood.

In this issue of Acta Haematologica, Inoue et al. [6] have evaluated the efficacy of rhTM in treating DIC complicating aHSCT. They divided DIC patients into 2 groups, treated with or without rhTM. In the rhTM-treated patients, the mean DIC score was significantly improved when compared with non-rhTM patients. Additionally, fibrinogen degeneration products, C-reactive protein, inflammatory cytokines, and high-mobility group box 1 were significantly decreased in rhTM-treated patients. Finally, the recovery rate from DIC was significantly higher in rhTM-treated patients. Inoue et al. [6] concluded that rhTM is effective against both DIC and systemic inflammatory complications after aHSCT.

Although aHSCT has made remarkable progress in therapeutic performance, DIC remains an important complication. Vascular endothelial vulnerability and endothelial dysfunction may be involved in the pathogenesis of DIC after aHSCT. Therefore, traditional anticoagu-

\section{KARGER}

(c) 2018 S. Karger AG, Basel

E-Mail karger@karger.com

www.karger.com/aha
Prof. Shosaku Nomura, MD

First Department of Internal Medicine, Kansai Medical University

2-5-1 Shin-machi, Hirakata

Osaka 573-1010 (Japan)

E-Mail shosaku-n@mbp.ocn.ne.jp 
lation therapies such as heparin or antithrombin III may not have the expected effect. The current study by Inoue et al. [6] probes further into the therapeutic role of rhTM in DIC after aHSCT. The authors propose that rhTM is effective against both DIC and systemic inflammatory complications after aHSCT. This new report challenges our previous understanding of therapeutic strategies for DIC after aHSCT. It also suggests that rhTM could allow more efficient treatment for DIC in critical aHSCT patients.

\section{References}

1 Levi M, Ten Cate H. Disseminated intravascular coagulation. N Engl J Med. 1999 Aug; 341(8):586-92.

2 Testa S, Manna A, Porcellini A, Maffi F, Morstabilini G, Denti N, et al. Increased plasma level of vascular endothelial glycoprotein thrombomodulin as an early indicator of endothelial damage in bone marrow transplantation. Bone Marrow Transplant. 1996 Aug; 18(2):383-8.
3 Saito H, Maruyama I, Shimazaki S, Yamamoto Y, Aikawa N, Ohno R, et al. Efficacy and safety of recombinant human soluble thrombomodulin (ART-123) in disseminated intravascular coagulation: results of a phase III, randomized, double-blind clinical trial. J Thromb Haemost. 2007 Jan;5(1):31-41.

4 Ikezoe T, Togitani K, Komatsu N, Isaka M, Yokoyama A. Successful treatment of sinusoidal obstructive syndrome after hematopoietic stem cell transplantation with recombinant human soluble thrombomodulin. Bone Marrow Transplant. 2010 Apr;45(4):783-5.
5 Sakai M, Ikezoe T, Bandobashi K, Togitani K, Yokoyama A. Successful treatment of transplantation-associated thrombotic microangiopathy with recombinant human soluble thrombomodulin. Bone Marrow Transplant. 2010 Apr;45(4):803-5.

6 Inoue Y, Matsunawa M, Sano F, Miura I: Efficacy of recombinant human soluble thrombomodulin in treating disseminated intravascular coagulation complicating allogeneic hematopoietic stem cell transplantation. Acta Haematol 2018, DOI: 10.1159/000492105. 